\title{
A batalha antológica \\ Resgate, inclusão e (re)fundação da tradição literária nas contra-antologias femininas de fins do século XX
}

\author{
Paula Candido Zambelli*
}

\section{Introdução}

A partir do século XIX, no Brasil, a evolução do gênero antológico parece indissociável dos processos que visavam à criação e transmissão de uma tradição literária genuinamente brasileira: os primeiros cânones românticos pós-independência materializaram-se nos parnasos e florilégios oitocentistas. No século XX, a forma antológica influenciou o conjunto das práticas letradas, definindo reputações literárias, princípios estéticos e ajudando a erguer os estreitos contornos da história cultural brasileira, responsáveis pela marginalização, entre outros grupos, das mulheres de letras, artes e ciência.

Nas últimas décadas do século XX, as antologias tornaram-se o objeto editorial de predileção da crítica feminista para a publicação dos textos de autoria feminina ausentes do cânone literário. O primeiro volume da antologia Escritoras brasileiras do século XIX, organizado por Zahidé Muzart, publicado pela Editora Mulheres, em 1999, é uma obra emblemática desse fenômeno.

Cânone, tradição, memória, identidade, herança, são alguns dos conceitos que emergem do estudo do gênero antológico em geral e, em particular, desse momento que pode ser descrito como o surgimento das chamadas contra-antologias (PALENQUe, 2007). Nesse contexto, pode-se indagar quais foram os elementos que fizeram da forma antológica campo de batalha privilegiado para a revisão da história cultural brasileira e quais foram, em decorrência dessa escolha, os impactos tanto para a historiografia literária quanto para o próprio gênero antológico.

Haja vista o protagonismo da obra Escritoras brasileiras do século XIX, acreditase que a análise aprofundada de seu projeto antológico, devidamente contextualizado na evolução do gênero no Brasil e em suas relações com a desconstrução e com a crítica feminista, é capaz de colaborar para uma compreensão mais ampla da problemática proposta.

Doutoranda em Estudos Lusófonos no Centre de Recherches sur les Pays Lusophones (Crepal),

Université Sorbonne Nouvelle - Paris 3, Paris, França. E-mail: pa.zambelli@gmail.com 


\section{A evolução do gênero antológico no Brasil}

No Ocidente, a forma antológica é praticada desde a Antiguidade. Contudo, as antologias modernas, como concebidas atualmente, são produto do século XIX (FrAISSE, 1997) e estão ligadas à formação dos Estados nacionais, sobretudo na América Latina: as antologias brasileiras oitocentistas foram poderosos vetores dos valores identitários nacionais - como a língua, a literatura e a cultura. ${ }^{1}$ Elas estabeleceram os fragmentos textuais de uma literatura brasileira e as bases para seu estudo sistematizado. Como destacou Regina Zilberman (1997, p. 20):

os românticos passaram pela etapa dos parnasos, com suas variantes (modulações, mosaico, meandro, harmonias, florilégios e grinaldas), e seus estudos tomaram os nomes de bosquejo, cursos e resumos. Mas, quando faziam isso, a história da literatura na Europa consolidava-se e fornecia a eles ideias e inspirações. Se não se atreveram a escrever a "história da literatura brasileira”, deram as coordenadas básicas para que seus sucessores, ainda que adversários do Romantismo, tivessem condições de adotar a denominação própria que o gênero tinha desde o início do século.

O longo processo de especialização que separaria os manuais de história literária das antologias tem como marcos as publicações da História da literatura brasileira (Romero, 1988) e da Antologia nacional, de 1895, primeira a utilizar a palavra antologia, em cujo prefácio lê-se:

O título de Antologia, muito de indústria o adotamos. [...] Em seus dois elementos efetivamente reúne a ideia da flor e a da palavra, que é a flor do entendimento [...] Ele também prevenirá o leitor benigno de que se não escandalize de quaisquer lacunas. Um ramilhete não é um horto botânico. Basta que formosas e aromáticas sejam as flores aqui reunidas, e que oferecemos à mocidade de ambos os países onde se fala português (BARRETO; LAET, 1895, p. 9).

Além da explicação etimológica, a passagem ilustra o problema fulcral do gênero, o da seleção. $\mathrm{O}$ ar despretensioso parece em desacordo com a observação de Marta Palenque (PALENQUe, 2007, p. 3) de que nada pode haver de inocente em uma antologia, uma vez que cada presença implica uma ausência - e, por que não dizer, uma marginalização, visto que não há escritoras nessa antologia, por exemplo. A Antologia nacional foi reeditada durante 74 anos e esteve presente nas salas de aula de todo o país, desempenhando um papel fundamental na formação da intelligentsia brasileira, incluindo um número expressivo de escritores canônicos que a citam em suas memórias como o primeiro contato, formador, com a literatura de língua portuguesa (RAzzINI, 20oo).

\footnotetext{
Tríade que Anne-Marie Thiesse (2001) situa na origem dos processos de criação das identidades
} nacionais europeias e que parece poder aplicar-se com justeza ao caso brasileiro. 
Na Era Vargas, a partir de 1930, as antologias consolidaram-se na educação nacional como um dos instrumentos de difusão e pedagogia empregados no projeto varguista de reformulação da identidade nacional, pilotado pelo Ministério da Educação. O ministério foi diretamente responsável, entre outras publicações, por uma série de antologias poéticas. As duas primeiras antologias publicadas pela Imprensa Nacional, organizadas pelo poeta Manuel Bandeira (1937; 1938), foram cruciais para que as antologias extrapolassem o ambiente escolar e atingissem o grande público, estendendo o alcance da pedagogia do nacional colocada em prática no período - vale sinalizar que, somando os dois períodos representados por Bandeira, os fragmentos de autoria feminino representam cerca de $2 \%$ da seleção e limitam-se à sete poemas de Francisca Júlia (1871-1920) entre os parnasianos (ZAMBELLI, 2015).

Tal cenário, assim como a afinidade entre gênero antológico e discurso dominante, persistiram por décadas, mesmo com o advento da crítica universitária ou, ainda, com a tendência regionalista de meados do século XX. Na segunda metade do século, gradualmente, a antologia perde espaço nas escolas, como livro didático, mas se vulgariza e encontra amplo espaço no mercado editorial, reapresentando seguidas vezes, apenas com arranjos diferentes, os mesmos cânones para públicos cada vez mais diversificados.

A frequente instrumentalização das antologias pelo discurso dominante explicase, em parte, pelo fato de esses objetos constituírem um espaço de coabitação e imbricamento dos discursos históricos, literário, estético e ideológico. Para Emmanuel Fraisse, apesar da aparente simplicidade, antologias constituem um verdadeiro "observatório do fato literário" (FraIsSE, 1997, p. 3). Veiculam, às vezes muito discretamente, uma certa ideia de literatura que se reflete tanto na seleção dos fragmentos literários quanto no aparato crítico que os acompanha. Cada antologia, cada novo conjunto, poderia ser descrita como espécie de mosaico textual cujo cimento é o discurso dominante de seu tempo presente.

É esse discurso compósito das antologias que determina "o ser ou não ser" (PAlengue, 2007, p. 3) dos escritores, ou seja, alcançar leitores, ter um lugar na história literária, ou tornar-se um desconhecido, um marginal. Ainda segundo a autora, a percepção desse sistema pelos grupos marginalizados está na origem do surgimento do que ela denomina contra-antologias. Um dos exemplos mais evidentes desse processo é, justamente, o da reação ao apagamento das vozes femininas do cânone nacional, tão conhecido e explicado hoje em dia.

\section{Desconstrução, crítica feminista e gênero antológico}

O surgimento das contra-antologias femininas, nas últimas décadas do século $\mathrm{XX}$, e sua adoção como instrumento de denúncia dos mecanismos excludentes da crítica tradicional, evidenciam as relações entre crítica feminista e desconstrução, 
já esmiuçada na importante obra coletiva Da tessitura ao texto (ZINANI; SANTOS, 2012). Desenvolvida por Jacques Derrida a partir de 1967, a desconstrução

consiste em desfazer, sem nunca destruir, um sistema de pensamento hegemônico e dominante. Desconstruir é de certo modo resistir à tirania do Um, do logos, da metafísica (ocidental) na própria língua em que é enunciada, com a ajuda do próprio material deslocado, movido com fins de reconstruções cambiantes (DERRIDA; Roudinesco, 2004, p. 9).

Os estudos de arqueologia literária, ou seja, a recuperação de autoras silenciadas e de textos de autoria feminina apagados, fração importante do conjunto de práticas e paradigmas próprios à crítica feminista, é uma desconstrução da primazia da história tradicional da literatura, por meio da apresentação de novas formas de ver o literário - ou novas ideias de literatura. Por se tratar de desconstrução, faz-se, precisamente, "na própria língua" e "com ajuda do próprio material" de origem, ou seja, através, entre outros suportes e discursos, das antologias, objeto fundamental para a construção do cânone tradicional, de vocação excludente.

As premissas de Derrida e a crítica feminista convergem, ainda, no combate a outros conceitos contidos no substrato das antologias tradicionais, como: o mito de que a literatura ocidental foi criada por escritores homens; a imagem do autor genial, superior ao seu tempo; e o conceito de uma literatura única.

Escritoras brasileiras do século XIX integra um movimento mundial iniciado pela The Norton anthology of literature by women (GILBERT; GUBAR, 1985), uma antologia transnacional que inclui excertos de obras de 219 escritoras, num período de seis séculos (do XIV ao XX). A obra pode ser contextualizada num ambiente intelectual fervilhante, de grande reivindicação, nos Estados Unidos, poucos anos após a publicação do importante artigo de Elaine Showalter (1981), "Feminist criticism in the wilderness". Ela responde com diversidade a uma tradição baseada na exclusividade, conforme destacam suas organizadoras:

Como a própria diversidade foi determinante para a evolução da crítica feminista - desde a sua preocupação inicial com as experiências compartilhadas das mulheres até seu interesse mais recente por questões e pressupostos complexos que emergem dos textos escritos em língua inglesa por escritoras de diferentes origens e influências geográficas, culturais, raciais, sexuais, religiosas e de classe -, então, pode-se dizer que a diversidade também definiu as revisões desta antologia (GILBERT; GuBAR, 2007; tradução nossa).

Nos anos que se seguem à sua publicação, antologias similares à da Norton foram publicadas em diversos países, atestando a intensa circulação das propostas da crítica feminista no mundo ocidental: Las voces olvidadas: antología crítica de narradoras mexicanas nascidas en el siglo XIX (Domenella; PASTERnAC, 1991), no 
México; Le scrittrici dell'Ottocento: da Eleonora de Fonseca Pimentel a Matilde Sera (SANvitale, 1995), na Itália; ou, ainda, Ellas cuentan: una antologia de relatos de escritoras colombianas, de la Colonia a nuestros dias (GIRALDO, 1998), na Colômbia.

Seus projetos antológicos contam uma série de características comuns. São publicadas por editoras relativamente marginais. Seu principal problema de pesquisa - a grande dificuldade de localização dos textos - é tratado ostensivamente nas instâncias prefaciais e relacionado à vontade de inclusão desses trabalhos que, não raramente, flexibilizam seus critérios para abranger um máximo de escritoras do passado. Não é raro, ainda, que seus prefácios apresentem a mesma estratégia discursiva, como segue: após a apresentação dos projetos de pesquisa dos quais são resultados, tratam dos problemas metodológicos enfrentados, abordam o lugar de esquecimento das mulheres e a questão do cânone utilizando metáforas recorrentes como vozes, silêncios, vazios, penumbras, traçam o panorama da situação feminina no século XIX e insistem na necessidade de que se leia os textos resgatados em seus devidos contextos. Por fim, anunciam o claro objetivo de revisão das histórias culturais locais.

\section{Projeto antológico de Escritoras brasileiras do século XIX}

Um projeto antológico é o resultado uma ação antológica - isto é, dos gestos combinados de seleção, organização e contextualização do fragmento literário, com toda sua intencionalidade. O projeto antológico de Escritoras brasileiras do século XIX foi amadurecido desde os anos 1980, no âmbito do grupo de trabalho "Mulher e literatura", da Associação Nacional de Pós-graduação e Pesquisa em Letras e Linguística (ANPOLL). Trata-se de uma obra de dimensões impressionantes: são 52 escritoras selecionadas por 16 pesquisadoras e mais de 900 páginas destinadas aos textos oitocentistas recuperados e ao aparato crítico que os contextualiza. Apenas no primeiro dos três volumes.

A primeira desconstrução operada por esse projeto é a da figura do antologista. Homem, geralmente só ou em duplas, com sua autoridade de leitor biônico, conhecedor e filtro da tradição. A organizadora Zahidé Muzart divide a cena com outras 15 pesquisadoras, com suas representações, ideologias, tendências críticas e metodológicas, que dão a configuração plural sem precedentes dessa antologia.

Os critérios de seleção também subvertem a postura depuradora das antologias tradicionais, mostrando-se extremamente abrangentes para desmentir a ideia de que mulheres começaram a publicar de forma considerável apenas no decorrer do século XX: todos os estados brasileiros nos quais foram encontrados textos femininos estão representados; assim como escritoras do século XVIII e estrangeiras que publicaram majoritariamente no Brasil. Ademais, incluiu-se grande variedade de gêneros literários: poemas, excertos de romances, contos, crônicas, atos de peças teatrais, ensaios, opúsculos, cartas e paratextos diversos. Nos textos 
introdutórios da antologia, não há considerações acerca de critérios estéticos, tampouco se faz referência a conceitos tão caros às antologias tradicionais quanto representatividade ou gênio.

Sabe-se que a organização do conteúdo selecionado, longe de ser trivial, é muito significativa para análise de uma antologia. Pode evidenciar, por exemplo, como o projeto apreende a história e sua relação com o literário, sua concepção do binômio texto/autoria, ou, ainda, posturas críticas, estabelecimento de hierarquias de gênero ou de outros valores estéticos. Nesse aspecto, as posturas das antologias tradicionais variam muito, e o que se pode dizer do projeto de Escritoras brasileiras é que apresenta uma tendência à valorização da autoria, apresentando as autoras por ordem cronológica de nascimento, com ausência de índices dos títulos antologizados. Os textos de época são acompanhados de um aparato crítico que muitas vezes os supera em número de páginas. Distantes da notícia biobibliográfica padrão ou dos estudos introdutórios gerais, assumem muitas vezes a forma de artigos científicos sobre as escritoras, seu tempo, sua luta e obra.

Esse fato leva à questão da contextualização do fragmento textual - que é aquilo que cria nexos entre as facetas da ação antológica. Na apresentação do volume a professora cubana Nara Araújo destaca o que é, a seu ver, a grande qualidade da obra. Para ela, a antologia "não se limita à acumulação cronológica e numérica dos textos de 52 autoras, olvidados ou mal lidos, mas chega à etapa superior, a da multiplicação e frutificação, na qual o documento perde a pátina, se livra da poeira e se vivifica ao ser situado e contextualizado" (ARAÚJo, 1999, p. 14).

$\mathrm{Na}$ relação entre texto e paratexto, manifesta-se a riqueza das antologias, o cimento que confere unidade ao mosaico e inculca valores. Comumente, o aparato crítico de uma antologia não excede nem em volume nem em importância o fragmento literário selecionado. Entretanto, em Escritoras brasileiras, a contextualização é parte essencial da experiência de leitura. Paratexto e texto confundem-se, não podendo ser apreendidos separadamente. Eis outra desconstrução do modelo antológico tradicional, com objetivo de versar sobre "o mundo feminino da época" (MuZART, 1999, p. 30) e de guiar a leitura, garantindo que o estilo datado muitas vezes empregado no texto oitocentista, que caiu em desuso ao longo do século $\mathrm{XX}$, não seja prematuramente julgado como de pouca qualidade literária, como gostariam os críticos da proposta de revisão da história cultural.

Essa sucessão de desconstruções tem como finalidade a desconstrução última da tradição excludente. Para tanto, na introdução da obra, Zahidé Muzart expõe sua filiação e a herança com a qual dialogará. Repertoria obras anteriores de duas ordens: primeiro, as que trataram de figuras femininas sem, contudo, antologizarem seus textos, como Mulheres ilustres do Brasil (1899), de Inês Sabino; A mulher rio-grandense (1907), de Andradina de Oliveira; e Mulheres do Brasil (em 4 volumes, de 1971 a 1993), de Henriqueta Galeno; e, segundo, as antologias stricto sensu, como Antologia feminina (1928), de Cândida de Brito; Perfis de musas, poetas e prosadoras brasileiras (1956), de Alzira Freitas Tacques; Vozes femininas da poesia brasileira 
(1959), de Domingos Carvalho da Silva; Em busca da Thargélia: poesia escrita por mulheres em Pernambuco no segundo oitocentismo (em 2 volumes, 1991 e 1996), de Luzilá Gonçalves Ferreira.

Esse panorama não serve apenas para mostrar a evolução de uma tradição, ainda que curta e tímida, na qual a antologia se insere, mas, principalmente, para mostrar o conhecimento dos limites desses trabalhos e a vontade de superá-los. Eis uma passagem fundamental da introdução do trabalho de Inês Sabino, Mulheres ilustres, antologizada em Escritoras brasileiras:

O presente livro não é um trabalho de floricultura. [...] Não é que a autora não goste de cultivar as belas filhas da primavera; mas nas Mulheres ilustres o cultivo das flores visa um outro fim que a emoção estética. [...] Eu quero ressuscitar, no presente, as mulheres do passado que jazem obscuras, devendo elas encher-nos de desvanecimento [...]. A mulher não deve viver somente palas virtudes, nem pelas graças: ela deve, necessita, agir pela inteligência, de acordo com os seus deveres morais e cívicos (MuZArT, 1999, p. 599).

Nela, há uma dupla associação das flores: com os poemas e com as mulheres. Ao recusar a etiqueta de floricultura - para não dizer antologia -, a autora está se posicionando ideologicamente contra um lugar autorizado às mulheres, visto em conformidade com sua natureza, que é o da leitura e da escrita da poesia amena. É uma postura de afrontamento interessante por utilizar uma das metáforas mais difundidas empregadas às antologias no centro de uma discussão sobre discurso e poder.

Escritoras brasileiras insere-se nessa tradição literária, herda essa retórica combativa da Inês Sabino, tão diferente da retórica do prefácio da Antologia nacional, lida na primeira parte deste trabalho, que justifica vagamente suas lacunas e abusa da tópica dos exercícios de modéstia, ou captatio benevolentiæ, assim como as muitas antologias que a seguiram. Ela confirma as palavras de Nara Araújo de que a antologia

pertence igualmente à tendência de uma crítica feminista interessada no estabelecimento de uma tradição literária escrita por mulheres: uma literatura própria. Porém vai mais além desse propósito, pois, ao mesmo tempo em que contribui para a história da escritura feminina no Brasil, participa da (re)escritura da sua história cultural (ARAújo, 1999, p. 14).

\section{Conclusão}

As contra-antologias femininas tencionavam denunciar a exclusão sistemática das mulheres, os limites do cânone literário, fundar uma tradição própria e, ao 
mesmo tempo, expandir os limites da história cultural vigente. Partiram da constatação da confluência histórica entre o gênero antológico e os discursos dominantes, compreenderam seus mecanismos mais profundos - sobretudo a tensão constante entre as funções de museu e manifesto que portam as antologias. Assim, puderam desconstruí-los e reformulá-los em conjuntos mais abrangentes.

Para a crítica feminista, o resultado dessa escolha e desse processo foi a fundação, de fato, de um patrimônio literário da autoria feminina, textual e crítico. Escritoras brasileiras do século XIX é uma obra de referência desde sua publicação, tanto para os estudos sobre autoria feminina, quanto para o conjunto da historiografia literária atual.

Para o gênero antológico, o surgimento das contra-antologias, não apenas as femininas, mas de outros grupos igualmente marginalizados, é um marco. Seu advento impôs uma reflexão ampla sobre as práticas antológicas no Brasil que, apesar da onipresença das antologias na vida cultural brasileira desde a Independência, ainda não ocorrera, colaborando para a emergência do próprio campo de estudo, ainda tímido e lacunar, mas em pleno desenvolvimento, sobre o gênero antológico no Brasil.

\section{Referências}

Araújo, Nara. Do vazio e do silêncio. In: Muzart, Zahidé (Org.). Escritoras brasileiras do século XIX. Florianópolis: Mulheres, 1999. v. 1.

BandeIra, Manuel. Antologia dos poetas brasileiros da fase parnasiana. Rio de Janeiro: Imprensa Nacional, 1938.

BAndeIra, Manuel. Antologia dos poetas brasileiros da fase romântica. Rio de Janeiro: Imprensa Nacional, 1937.

Barreto, Fausto; Laet, Carlos de. Antologia nacional. Rio de Janeiro: Francisco Alves, 1895 .

Derrida, Jaques; Roudinesco Elizabeth. De que amanhã... diálogo. Tradução de André Telles. Rio de Janeiro: J. Zahar, 2004.

Domenella, Ana; Pasternac, Nora. Las voces olvidadas: antología crítica de narradoras mexicanas nacidas en el siglo XIX. México, D.F.: El Colegio de México, 1991.

FraIsSE, Emmanuel. Les anthologies en France. Paris: PUF, 1997.

Gilbert, Sandra; Gubar, Susan (Org.). The Norton anthology of literature by women: the traditions in English. New York: W.W. Norton \& Co, 1984.

Gilbert, Sandra; Gubar, Susan (Org.). The Norton anthology of literature by women: the traditions in English. 3. ed. New York: W.W. Norton \& Co, 2007. 
Giraldo, Luz Mery (Org.). Ellas cuentan: una antología de relatos de escritoras colombianas, de la Colonia a nuestros días. Santafé de Bogotá: Seix Barral, 1998.

Muzart, Zahidé L. (Org.). Escritoras brasileiras do século XIX: antologia. 2. ed. Florianópolis: Mulheres; Santa Cruz do Sul: EDUNISC, 1999.

Palendue, Marta. Cumbres y abismos: las antologías y el canon. Ínsula, Barcelona, n. 721, p. 3-4, 2007. Disponível em: <https://dialnet.unirioja.es/servlet/articulo? codigo $=2226403>$. Acesso em: 27 mar. 2018.

RAzZINI, Márcia. O espelho da nação: a antologia nacional e o ensino de português e de literatura (1838-1971). 200o. Tese (Doutorado em Literatura Brasileira) - Universidade Estadual de Campinas, Campinas, 20oo. Disponível em: <http:// repositorio.unicamp.br/jspui/handle/REPOSIP/270144>. Acesso em: 27 mar. 2018.

Romero, Sílvio. História da literatura brasileira. Rio de Janeiro: Garnier, 1988.

Sanvitale, Francesca. Le scrittrici dell'Ottocento: da Eleonora de Fonseca Pimentel a Matilde Serao. Roma: Istituto Poligrafico e Zecca dello Stato, 1995.

Showalter, Elaine. Feminist criticism in the wilderness. Critical Inquiry, Chicago, v. 8, n. 2, p. 179-205, 1981. Disponível em: <lhttp://www.journals.uchicago.edu/doi/ 10.1086/448150>. Acesso em: 27 mar. 2018.

Thiesse, Anne-Marie. La création des identités nationales: Europe, $\mathrm{XVIII}{ }^{\mathrm{e}}-\mathrm{XX}^{\mathrm{e}}$ siècle. Paris: Éditions du Seuil, 2001.

Zambelli, Paula C. Anthologies littéraires brésiliennes et identité nationale sous l'Estado Novo (1937-1945). 2015. Dissertação (Mestrado em Estudos Lusófonos) Université Sorbonne Nouvelle, Paris, 2015.

Zilberman, Regina. Uma teoria para a história da literatura no Brasil. Cadernos do Centro de Pesquisas Literárias da PUC-RS, Porto Alegre, v. 3, n. 1, p. 20-26, 1997. (Anais do I Seminário Internacional de História da Literatura).

Zinani, Cecil; Santos, Salete (Org.). Da tessitura ao texto: percursos de crítica feminista. Caxias do Sul: EDUSC, 2012.

Recebido em 11 de outubro de 2017.

Aprovado em 8 de novembro de 2017. 


\section{Resumo/Abstract/Resumen}

A batalha antológica: resgate, inclusão e (re)fundação da tradição literária nas contra-antologias femininas de fins do século $\mathrm{XX}$

\section{Paula Candido Zambelli}

Desde o século XIX, o gênero antológico desempenha um papel fundamental na fixação e na transmissão da tradição literária brasileira. Constantemente instrumentalizado pelos discursos dominantes, participou do processo de marginalização das mulheres de letras no país. A partir dos anos 1980, na esteira da desconstrução, a crítica feminista, por sua vez, serviu-se das chamadas contra-antologias para o resgate dos textos de autoria feminina apagados. A análise de Escritoras brasileiras do século XIX: antologia, ilustra esse processo e aponta para o fato de que a escolha do gênero como campo de batalha para a revisão da história literária operou, ao mesmo tempo, um alargamento dos limites da história cultural vigente e uma desconstrução da própria forma antológica.

Palavras-chave: crítica feminista, historiografia literária, antologia.

The Anthological Battle: The Rescue, Inclusion and (re)Establishment of the Literary Tradition in Female Counter-Anthologies of the Late Twentieth Century

\section{Paula Candido Zambelli}

Since the nineteenth century, anthologies have played a key role in the establishment and dissemination of Brazil's literary tradition. However, through constant instrumentalization by the dominant discourse these anthologies played a role in the marginalization of women of letters in the country. In the wake of Deconstruction in the 1980's, Feminist Literary Criticism began to use so-called counteranthologies to rescue long-forgotten texts by female writers. The analysis of Escritoras brasileiras do século XIX: antologia illustrates this process and demonstrates that the choice of this genre as a battleground to reappraise literary history has resulted both in a broadening of the limits of present-day cultural history and in a deconstruction of the anthological format itself.

Keywords: feminist literary criticism, literary historiography, anthology.

La batalla antológica: rescate, inclusión y (re)fundación de la tradición literaria en las contra-antologías femeninas de fines del siglo $\mathrm{XX}$

\section{Paula Candido Zambelli}


Desde el siglo XIX, el género antológico desempeña un papel fundamental en la fijación y la transmisión de la tradición literaria brasileña. Constantemente instrumentalizado por los discursos dominantes, participó en el proceso de marginación de las mujeres de letras en el país. A partir de los años 1980, inspirada en la Desconstrucción, la Crítica Feminista, a su vez, se sirvió de las llamadas contraantologías para el rescate de los textos de autoría femenina olvidados. El análisis de Escritoras brasileiras do século XIX: antologia, ilustra este proceso y señala el hecho de que la elección del género antológico como campo de batalla para la revisión de la historia literaria operó, al mismo tiempo, una ampliación de los límites de la historia cultural vigente y una deconstrucción de la propia forma antológica.

Palabras clave: crítica feminista, historiografía literaria, antología. 